Baoan-Feng

https://doi.org/10.26881/pwe.2018.43.06

Xingping-Zhou

Quzhou College (China)

fba1986@126.com

\title{
The focus of public discourse on child abuse in kindergartens: analysis of articles on child abuse in newspapers of China from 2010 to $2017^{1}$
}

\begin{abstract}
Summary
As a social phenomenon, child abuse in kindergartens is not only an educational but also a legal issue. This study analyzed 423 critical articles on child abuse in kindergartens published by 103 newspapers in China from 2010 to 2017. The results of the research are as follows: (1) The change of public opinion on child abuse conforms to the law of public opinion development in the latent period, outbreak period, spread period, repetition period, remission period and long tail period of the dissemination of hot topics of public opinion; (2) The range of social groups concerned about child abuse has been expanding year by year, until 2017, a total of 22 categories of social groups have paid attention to child abuse; (3) The focus of public attention on the child abuse incidents includes 23 aspects, such as the supervision responsibility, harm, punishment, system, prevent, treatment and morality. Among them, it mainly focuses on supervision and rule of law, and lacks humanistic care for preschool teachers.
\end{abstract}

Keywords: kindergarten, child abuse, newspapers, public opinion

\section{Introduction}

\subsection{Child abuse in kindergartens is an adverse social issue which has aroused widespread concern in society}

Child abuse is the abuse and neglect that occurs to children under 18 years of age. It includes all types of physical and/or emotional ill-treatment, sexual abuse, neglect, negligence and commercial or other exploitation (World Health Organization 2016). Child abuse is a global problem, an analysis of nationally representative survey data on the prevalence of violence against children in 96 countries estimates that 1 billion children globally - over half of all children aged 2-17 years - have experienced emotional, physical or sexual violence in the past year (Hillis, Mercy, Amobi et al. 2016). Child abuse with serious life-long consequences, which has enormous immediate and long-term repercussions. Beyond death, physical injury and disability, violence can lead to stress that impairs brain development and damages the nervous and immune systems. This, in turn,

1 Sources of funding: Major Humanities and Social Sciences Project Tackling Plan of Universities in Zhejiang Province in 2013 (NO. 2013QN058). 
is associated with delayed cognitive development, poor school performance and dropout, mental health problems, suicide attempts, increased health-risk behaviours, revictimization and the perpetration of violence (World Health Organization 2019).

In recent years, the "anti-education" phenomenon of child abuse has repeatedly erupted, which has aroused widespread concern in society of China. Child abuse in kindergartens has once again become the focus of public concern, and the preschool education has been pushed to the whirlpool of public opinion. A case of child abuse in kindergartens has repeatedly stimulated the sensitive nerves of the whole society, aroused widespread concern of the public and the media, and set off a storm and climax of public opinion. The critical articles and correspondence articles about child abuse in kindergartens published in newspapers are full of the public's vision and also influence the trend of public opinion.

\subsection{The reasons for analyzing and studying newspaper commentary articles on child abuse in kindergartens}

Newspaper is an important carrier of mass information dissemination. In the contemporary era, people can easily and quickly access and obtain relevant information through various means, such as newspapers, newspaper websites, news clients, WeChat subscription, etc., which have the characteristics of popular readers, convenient dissemination and wide influence. As the official media, newspapers publish articles with high credibility and authority, with the function of reflecting and guiding public opinion. The newspaper reports about child abuse in kindergartens reflect the attitude and cognition of the public to a great extent, and reflect the direction of public opinion of the society. The newspaper news articles are divided into three types: news, communication, and commentary. This paper takes communication and commentary articles as the research object.

Based on the statistics of the critical articles on child abuse in kindergartens published in newspapers from 2010 to 2017, this paper focuses on the analysis of the focus of the article and the author's attitude, cognition and value standpoint on child abuse in kindergartens. After that, the author makes a dialectical analysis of his views and opinions, organizes and summarizes his reasonable suggestions, and finally forms a relatively complete proposal, which is of great practical significance in preventing and dealing with child abuse in kindergartens.

\section{Research Method}

This research has adopted the strategy of "Stratified Sampling" and "Holistic Sampling" to select information, which sampling articles related to all newspapers from 2010 to 2017. In this study, the CNKI and BAIDU search engine were used as the main retrieval tools to search newspaper articles from 2010 to 2017 with the words "child abuse", "corporal punishment of children", "indecent" and "sexual assault" as the full text respectively. Those not related to kindergartens such as child abuse in primary and secondary schools, family and social child abuse, and articles with different titles but the same contents but not belonging to the first issue were eliminated. In addition, 423 articles were searched out. 
In this study, the Excel software was used to collect statistics of the collected articles, and the Word Frequency Statistics Tool 3.0 software developed by Agile Software Studio was used to retrieve and statistics high-frequency vocabulary.

\section{Results and Discussion}

\subsection{Annual distribution of newspaper articles on child abuse in kindergartens from 2010 to 2017}

\subsubsection{Results}

Between 2010 and 2011, seven articles on child abuse in kindergartens were published in the newspapers. This shows that child abuse in kindergartens has not attracted enough attention from the public. Afterwards the "Child Abuse in Wenling Kindergarten in Zhejiang Province" in 2012 ignited the newspaper public opinion field and aroused strong public concern. After this incident the number of newspaper articles reached a peak (134 articles), and the public opinion heat reached a peak. From 2013 to 2016, although there have been many incidents of child abuse in kindergartens, such as the "Shanxi Xi'an Kindergarten Feeding Incident" in 2014, which attracted the attention of the newspaper media, the popularity of newspaper public opinion declined year by year, and the child abuse in kindergartens tended to a low tide in newspaper public opinion. The change in the trend of public opinion of child abuse in kindergartens accords with the law of public opinion, which is incubation period, outbreak period, spread period, recurrence period, remission period and long tail period (Fuji-Chen, Gaili-Hu 2014). In 2017, the "Shanghai Ctrip Abuse Incident" and "Beijing RYB Education Abuse Incident" once again ignited the newspaper public opinion field, the newspaper on the child abuse incident in kindergartens again soared (Figure 1).

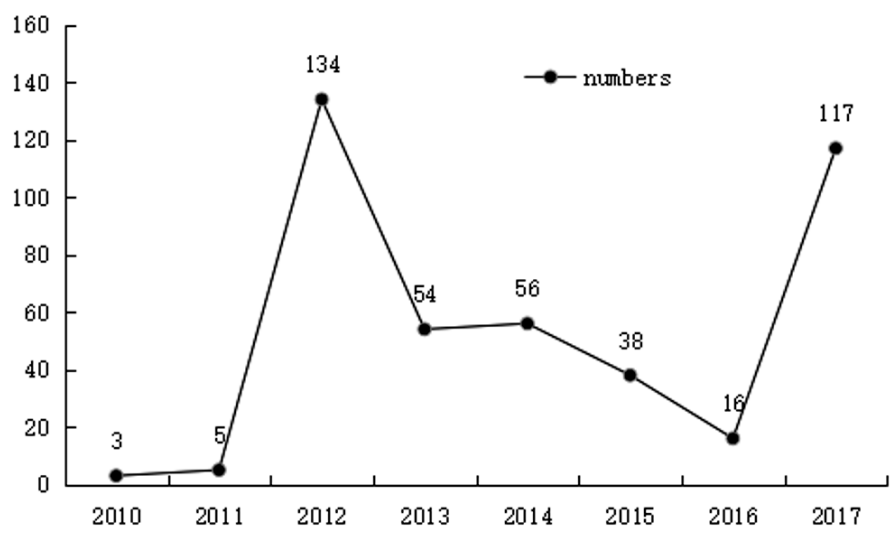

Figure 1. Annual distribution of newspaper articles reported on child abuse in kindergartens from 2010 to 2017 


\subsubsection{Discussion}

The public opinion spread of child abuse in kindergartens is characterized by long incubation period, rapid outbreak, long shock period and rapid decline. Public opinion has paid more attention to child abuse in kindergartens, which are manifested in the following two aspects. Firstly, the number of newspaper organizations reporting such incidents was increasing. According to statistics, the child abuse in the period from 2010 to 2017 caused widespread attention in 103 newspapers in the press, and the number of presses that published articles on child abuse in kindergartens expanded from 3 in 2010 to 48 in 2017. Secondly, the number of newspaper articles reporting child abuse incidents was generally on the rise. According to statistics, the number of newspaper articles on such incidents increased from 3 in 2010 to 134 in 2012, and from 54 in 2013 to 117 in 2017. Generally speaking, the trend of public opinion is increasing.

\subsection{Distribution of authors in newspaper articles on child abuse in kindergartens from 2010 to 2017}

\subsubsection{Results}

According to statistics, as for the author group of newspaper articles, the author group of newspaper articles has the characteristics of diversification of identity and widespread occupation. The authors of the articles include 10 categories of identities: media commentators, journalists, educators, government officials, academics, business staff, lawyers, doctors, newspapers, other, etc. (Table 1).

Table 1. Distribution of authors in newspaper articles on child abuse in kindergartens from 2010 to 2017

\begin{tabular}{|c|c|c|c|}
\hline Author group & Number of articles & Author group & Number of articles \\
\hline Media commentators & 173 & Business staff & 5 \\
\hline Journalists & 125 & Lawyers & 3 \\
\hline Educators & 63 & Doctors & 2 \\
\hline Government officials & 38 & Newspaper offices & 2 \\
\hline Academics & 10 & Other & 2 \\
\hline
\end{tabular}

Among them, the author groups who pay more attention to child abuse in kindergartens are the press (media commentators, journalists), the educational circles (universities, primary and secondary schools, kindergarten teachers), the judiciary (procuratorate staff, court staff, lawyers).

\subsubsection{Discussion}

The child abuse in kindergartens is not only an educational issue, but also a social issue. Every child abuse attracted close and extensive attention of the society. The social groups 
concerned about such incidents were increasing year by year. In the new author group of newspaper articles on child abuse, in addition to 2015 and 2016, new author groups appeared in other years. In terms of the annual distribution of the author's identity type, the overall trend was increasing. The statistical results show that the authorship type had increased from three in 2010 to 13 in 2012, and increased to 15 in 2017. According to statistics, the author groups concerned about child abuse in kindergartens from 2010 to 2017 included media commentators, journalists, educators, judicial staff, academic institutions, government workers, deputies, CPPCC members, corporate staff, women's federations, lawyers and doctors, etc. The above statistics show that the child abuse in kindergartens had attracted more and more attention from social groups.

\subsection{The focus of attention of authors of newspaper articles on child abuse in kindergarten from 2010 to 2017}

\subsubsection{Results}

This study uses the Word Frequency Statistics Tool 3.0 software developed by Agile Software Studio to count the word frequency of 423 newspaper articles on child abuse events of kindergartens.

As shown in Table 2, there are 23 words in the articles whose frequency is more than 130 times, including "supervision", "responsibility", "harm", "treatment", "morality", "crime", "system" "psychological", "punishment", "prevention" and so on, which are the focus of the authors.

Table 2. Distribution of high-frequency word coverage in newspaper articles on child abuse in kindergartens from 2010 to 2017 (Top ten)

\begin{tabular}{|r|c|c|c|c|}
\hline No. & $\begin{array}{c}\text { High-frequency } \\
\text { word }\end{array}$ & Frequency & $\begin{array}{c}\text { The number of } \\
\text { articles covered }\end{array}$ & Coverage rate \\
\hline 1 & Supervision & 1482 & 306 & $72.35 \%$ \\
\hline 2 & Responsibility & 858 & 256 & $68.52 \%$ \\
\hline 3 & Harm & 700 & 210 & $59.65 \%$ \\
\hline 4 & Treatment & 692 & 170 & $30.19 \%$ \\
\hline 5 & Morality & 675 & 186 & $47.90 \%$ \\
\hline 6 & Crime & 596 & 118 & $47.57 \%$ \\
\hline 7 & System & 557 & 197 & $47.53 \%$ \\
\hline 8 & Psychological & 545 & 167 & $35.52 \%$ \\
\hline 9 & Punishment & 523 & 201 & $46.10 \%$ \\
\hline 10 & Prevention & 474 & 195 & $44.75 \%$ \\
\hline
\end{tabular}

The coverage of high-frequency words such as "supervision", "responsibility", "harm", "morality", "crime", "system", "punishment" and "prevention" is above more than 40\%, which were paid more attention. Specifically, the authors of the newspaper articles emphasize that child abuse was a criminal act that had caused great harm to children and that 
the abusers must be severely punished and condemned. At the same time, they called on the government to improve the legal system, strengthen the safety supervision of kindergartens and assume the corresponding responsibilities, improve the professional ethics of teachers and prevent child abuse in kindergartens. However, the concern for "treatment" and "psychology" was relatively lower (Table 2).

\subsubsection{Discussion}

Public opinion focused on supervision and the rule of law in the child abuse in kindergartens, and lacked humanistic care for preschool teachers. Statistics found that there were 105 newspaper articles with the theme of "lack of supervision", accounting for $24.82 \%$ of the total number of articles. The word "supervision" appeared 1482 times in 423 newspaper articles, ranking first among 23 focus points; the word "supervision" appeared in 306 newspaper articles, with $72.35 \%$ coverage of all articles. From ordinary teachers to scholars, from the media to legal workers, from ordinary people to public officials, they had issued calls for improving legislation and strengthening legal management. But they had reached a consensus on the issue of administering schools according to law. In my opinion, the law is only one of the means to prevent and deal with the child abuse incidents, but it does not eradicate the phenomenon of child abuse.

For a long time, news commentary had basically focused on events, and it had rarely been seen as the focus of comment on people and neglect of people, which was a shortcoming of news commentary. When public opinion paid attention to child abuse in kindergartens, a series of problems such as low treatment and pressure of teachers, bottlenecks of teachers' professional development, psychological problems of teachers and so on had come into the public attention and attracted people's attention. Research shows that insufficient income is the most important factor in child abuse by caregivers (Indiana Department of Child Services 2018). When the child abuse occurred, the overwhelming majority of the concerns were about how to punish teachers who abuse child, and the humanistic care for the kindergarten teachers was less attention.

\section{Conclusion and recommendations}

Public opinion has paid more attention to child abuse in kindergartens from 2010 to 2017, the author group of newspaper articles has the characteristics of diversification of identity and widespread occupation. The focus of the newspaper authors on the phenomenon of child abuse in kindergartens is diversified. There are various factors influencing the occurrence of child abuse in kindergartens, the imperfect legal system of child protection and the defective management system of preschool education are the fundamental reasons for the frequent occurrence of child abuse in kindergartens. With the continuous advancement of social civilization, people's awareness and concepts of child protection have gradually increased, and the tolerance for child abuse in kindergartens has become lower and lower, 
and the shortcomings in law have become more and more dazzling. The low quality and low professional level of some kindergarten teachers are the direct reasons for the frequent occurrence of child abuse in kindergartens. The low overall treatment of preschool teachers, the pressure of work, the small space for career development, the lack of on-the-job training channels, the outstanding mental health problems of teachers, and the lack of guidance mechanism are the incentives for frequent child abuse incidents in kindergartens.

We believe that the public and the media should comment on teachers from a different perspective when they pay attention to and comment on child abuse in kindergartens. In particular, we need to maintain a normal attitude, not to deify teachers, nor demonize teachers, not to swing between praise and slander. In the treatment of child abuse in kindergartens: first, the state should improve the child protection legal system. Developing and strengthening legal protections and policies for children, in conjunction with the means to enforce these protections, is a prudent step in preventing violence against children (World Health Organization 2016). It is necessary for the government to enact special laws to prevent child abuse, to implement a compulsory reporting system for those who are most likely to come into contact with child abuse cases (e.g. educators, medical workers, social workers, etc.), and to specifies the definition, type, judgment criteria, sanctions methods, institutional settings, and judicial protection of child abuse (Juan-Shen, Yingqi-Cai 2013). Second, establish and improve the preschool education management system and mechanism from the central to the local integration, clarify the powers and responsibilities of relevant government departments at all levels, and incorporate the implementation of kindergarten safety supervision responsibilities into the annual performance appraisal of governments at all levels (Baoan-Feng, Xingping-Zhou 2016). Third, the legal and economic status of kindergarten teachers should be clarified to enhance their sense of belonging and happiness. Fourth, we should strengthen the training of kindergarten teachers, improve their professional level and teachers' ethics, ensure their professional status, enhance their professional identity and improve teachers' ethical level. Through the supervision and disciplinary measures the government achieves the goal of preventing preschool teachers from dare-not to can-not abuse child. It is also necessary to try to eliminate the subjective motives of teachers to carry out harm and abuse, so that they are not willing to abuse child.

\section{References}

World Health Organization (2016), Child maltreatment. https://www.who.int/en/news-room/fact-sheets/detail/child-maltreatment.

Hillis S., Mercy J., Amobi A. et al. (2016), Global prevalence of past-year violence against children: a systematic review and minimum estimates. "Pediatrics", 137 (3).

World Health Organization (2019), Violence and Injury Prevention. https://www.who.int/violence_injury_prevention/violence/child/en/.

Fuji-Chen, Gaili-Hu (2014), On the Spread Pattern of Network Public Opinion Hot Topics. "Journal in Intelligence", 33 (1). 
Indiana Department of Child Services (2018), 2016 Annual Report of Child Abuse \& Neglect Fatalities in Indiana. https://www.in.gov/dcs/files/2016_Fatality_Report.pdf.

World Health Organization (2019), INSPIRE: seven strategies for ending violence against children. https://apps. who.int/iris/bitstream/handle/10665/246212/WHO-NMH-NVI-16.7-chi.pdf?sequence $=4$.

Juan-Shen, Yingqi-Cai (2013), The Law Protection of Child Abuse in America - taking the state model of child abuse protocol in Georgia for example. "Studies in Preschool Education", (5).

Baoan-Feng, Xingping-Zhou (2016), On Death Incidents of Children in Kindergartens from 2010 to 2015 in China. "Studies in Preschool Education", (2). 